\title{
Optical and Magnetic Properties of Fe Doped ZnO Nanoparticles Obtained by Hydrothermal Synthesis
}

\author{
Xiaojuan Wu, ${ }^{1,2}$ Zhiqiang Wei, ${ }^{1,2}$ Lingling Zhang, ${ }^{2}$ Xuan Wang, \\ Hua Yang, ${ }^{1,2}$ and Jinlong Jiang ${ }^{2}$ \\ ${ }^{1}$ State Key Laboratory of Advanced Processing and Recycling Nonferrous Metals, Lanzhou University of Technology, \\ Lanzhou 730050, China \\ ${ }^{2}$ School of Science, Lanzhou University of Technology, Lanzhou 730050, China
}

Correspondence should be addressed to Zhiqiang Wei; zqwei7411@163.com

Received 25 May 2014; Revised 13 June 2014; Accepted 16 June 2014; Published 3 July 2014

Academic Editor: Chee Kiang Ivan Tan

Copyright (C) 2014 Xiaojuan Wu et al. This is an open access article distributed under the Creative Commons Attribution License, which permits unrestricted use, distribution, and reproduction in any medium, provided the original work is properly cited.

\begin{abstract}
Diluted magnetic semiconductors $\mathrm{Zn}_{1-x} \mathrm{Fe}_{x} \mathrm{O}$ nanoparticles with different doping concentration $(x=0,0.01,0.05,0.10$, and 0.20$)$ were successfully synthesized by hydrothermal method. The crystal structure, morphology, and optical and magnetic properties of the samples were characterized by X-ray diffraction (XRD), energy dispersive spectrometer (EDS), high-resolution transmission electron microscopy (HRTEM), Raman scattering spectra (Raman), photoluminescence spectra (PL), and the vibrating sample magnetometer (VSM). The experiment results show that all samples synthesized by this method possess hexagonal wurtzite crystal structure with good crystallization, no other impurity phases are observed, and the morphology of the sample shows the presence of ellipsoidal nanoparticles. All the $\mathrm{Fe}^{3+}$ successfully substituted for the lattice site of $\mathrm{Zn}^{2+}$ and generates single-phase $\mathrm{Zn}_{1-x} \mathrm{Fe}_{x} \mathrm{O}$. Raman spectra shows that the peak shifts to higher frequency. PL spectra exhibit a slight blue shift and the UV emission is annihilated with the increase of $\mathrm{Fe}^{3+}$ concentration. Magnetic measurements indicated that Fe-doped $\mathrm{ZnO}$ samples exhibit ferromagnetic behavior at room temperature and the saturation magnetization is enhanced with the increase of iron doping content.
\end{abstract}

\section{Introduction}

Diluted magnetic semiconductors (DMSs) are referred to as nonmagnetic semiconductors in which a small fraction of host cations are replaced by transition metal or rare-earth ions, with both spin and charge degrees of freedom in a single material $[1,2]$. In recent years, DMSs have been under intense research due to their potential applications in spinbased multifunctional electronic devices, such as ultraviolet absorbers, optoelectronics, spin field-effect transistors, fieldemission devices, gas sensors, nonvolatile memory devices, and quantum computer [3-8]. Of all the oxide diluted magnetic semiconductors, the transition metal (TM) doped $\mathrm{ZnO}$ has been identified as a promising one, because the host material $\mathrm{ZnO}$ is a chemically and thermally stable $n$-type II-VI compound semiconductor with a wide band gap energy $(3.37 \mathrm{eV})$ and a large exciton binding energy (60 meV) [9-11]. During the past years, transition metal doped $\mathrm{ZnO}$ has been doped into the $\mathrm{ZnO}$ lattice to modulate the local electronic structure and cause dramatic changes in their optical and electromagnetic properties [12-15]. Various methods have been used to synthesize TM doped $\mathrm{ZnO}$ nanoparticles: some experimental results observed the room temperature ferromagnetism in $\mathrm{ZnO}: \mathrm{Fe}$ system, but the experimental results were contradictory, and the theoretical explanation about the origin of the magnetism is still not mature [16-20]. However, there are very few reports on the magnetic behavior of transition metal doped $\mathrm{ZnO}$ synthesized using hydrothermal method. Thus, in this paper, our aim is to synthesize $\mathrm{Zn}_{1-x} \mathrm{Fe}_{x} \mathrm{O}$ nanoparticles with different concentration using hydrothermal method and to study their structural, optical, and magnetic properties.

In this paper, diluted magnetic semiconductors $\mathrm{Zn}_{1-x} \mathrm{Fe}_{x} \mathrm{O}$ nanoparticles with different doping consistency $(x=0,0.01,0.05,0.10$, and 0.20$)$ were synthesized by hydrothermal method. And the crystal structure, 
morphology, and optical and magnetic properties of the samples were characterized by X-ray diffraction (XRD), energy dispersive spectrometer (EDS), high-resolution transmission electron microscopy (HRTEM), Raman scattering spectra (Raman), photoluminescence spectra (PL), and the vibrating sample magnetometer (VSM).

\section{Experimental}

$\mathrm{Zn}_{1-x} \mathrm{Fe}_{x} \mathrm{O}(x=0,0.01,0.05,0.10$, and 0.20) nanoparticles were prepared by hydrothermal method. All materials were of analytical grade and used without further purification in this study. In a typical experiment, zinc acetate $\left(\mathrm{Zn}\left(\mathrm{CH}_{3} \mathrm{COO}\right)_{2} \cdot 2 \mathrm{H}_{2} \mathrm{O}, 99.0 \%, \mathrm{AR}\right)$ and ferric nitrate $\left(\mathrm{Fe}\left(\mathrm{NO}_{3}\right)_{3} \cdot 9 \mathrm{H}_{2} \mathrm{O}, \geq 99.0 \%, \mathrm{AR}\right)$ were mixed together according to the required amounts of the corresponding chemical reagents and dissolved into absolute alcohol under magnetic stirring at room temperature. Then cetyltrimethylammonium bromide (CTAB, $\geq 99.0 \%, A R$ ) was added to the above solution; meanwhile, sodium hydroxide $(\mathrm{NaOH}, \geq 96.0 \%$, AR) was dissolved into absolute ethanol and introduced into the above solution. After being stirred for $30 \mathrm{~min}$, the mixture was transferred into a $45 \mathrm{~mL}$ Teflon lined stainless steel autoclave. The hydrothermal synthesis was heated to $180^{\circ} \mathrm{C}$ and maintained for $24 \mathrm{~h}$ in an oven and then cooled down to the room temperature naturally. The obtained products were washed with distilled water and absolute ethanol several times and dried at $60^{\circ} \mathrm{C}$ for $24 \mathrm{~h}$. Finally, the samples were obtained.

The crystalline structures of the samples were examined by a rotating-target X-ray diffractometer (Japan Rigaku D/Max-2400) equipped with graphite monochromatized $\mathrm{CuK} \alpha$ radiation $(\lambda=1.54056 \AA, 40 \mathrm{kV}, 100 \mathrm{~mA})$. The samples were scanned in the angular range from 10 to $90^{\circ}(2 \theta)$ with scanning rate $0.005^{\circ} / \mathrm{s}$ and step size $0.02^{\circ}$. The morphology and microstructure of the samples were observed through transmission electron microscopy (TEM, Japan JEOL JEM $1200 \mathrm{EX})$, the corresponding selected-area electron diffraction (SAED), and high-resolution transmission electron microscopy (HRTEM, JEM-2010). The chemical composition of the products was verified by energy dispersive spectroscopy (EDS) at an acceleration voltage of $200 \mathrm{keV}$ in TEM. Raman spectral measurements at room temperature in the energy region between 100 and $1500 \mathrm{~cm}^{-1}$ were carried out using a micro-Raman spectrometer (HR800) with $525 \mathrm{~nm}$ line of He-Ne ion laser as exciting light source. Photoluminescence (PL) spectra were performed at $266 \mathrm{~nm}$ wavelength using a PerkinElmer spectrophotometer with a HeCd laser as excitation source. Magnetic hysteresis loops were investigated at room temperature using a vibrating sample magnetometer (VSM, Lakeshore 7304) with an applied field from -12000 Oe to 12000 Oe.

\section{Results and Discussion}

The phase purity and crystal structure of the $\mathrm{Zn}_{1-x} \mathrm{Fe}_{x} \mathrm{O}$ samples were examined by XRD. Figure 1 shows the typical XRD patterns of $\mathrm{Zn}_{1-x} \mathrm{Fe}_{x} \mathrm{O}(x=0,0.01,0.05,0.10$, and

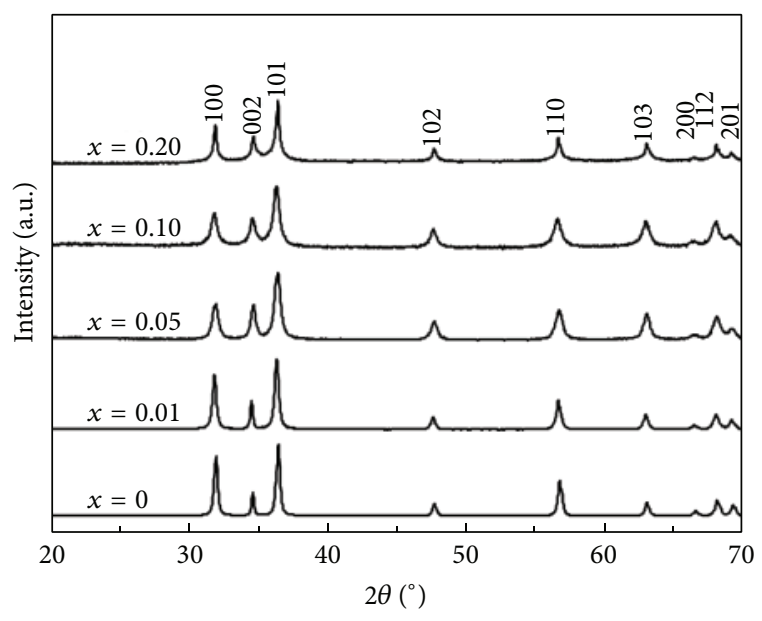

FIGURE 1: XRD patterns of $\mathrm{Zn}_{1-x} \mathrm{Fe}_{x} \mathrm{O}$ nanoparticles.

$0.20)$ nanoparticles. It is clearly observed from the pattern that all the diffraction peaks can be well corresponding to the diffractions of (100), (002), (101), (102), (110), (103), (200), (112), (201), and (202) planes of single-phase hexagonal wurtzite structure with the space group $6_{3} \mathrm{mc}$, respectively. All the diffraction peaks are in good agreement with the values of the standard spectrum (JCPDS 01-079-2205). In addition, there are no traces of impurity or secondary phases within the detection limit of XRD and there are no obvious diffraction patterns of $\mathrm{Fe}$ species such as $\mathrm{Fe}, \mathrm{Fe}_{2} \mathrm{O}_{3}$, and $\mathrm{Fe}_{3} \mathrm{O}_{4}$ in the samples where the doping atomic percentage is from $1 \%$ to $20 \%$. These results indicate that all $\mathrm{Fe}$ ions were incorporated in the lattice of the host crystals, the products consist of pure phase, and no characteristic peaks can be found from other impurities.

For Fe-doped $\mathrm{ZnO}$ dilute magnetic semiconductors, the peak position of the doped $\mathrm{ZnO}$ samples shifts to lower angles compared with pure $\mathrm{ZnO}$, and also there is a decrease in the intensity of peaks with the Fe doping concentration. This shifting as well as decrease in intensity of the characteristic peak clearly indicates the successful incorporation of $\mathrm{Fe}$ in the $\mathrm{ZnO}$ matrix, which can be attributed to the difference of ion radius of $\mathrm{Zn}^{2+}(0.74 \AA)$ comparing with that of $\mathrm{Fe}^{3+}(0.64 \AA)$. It is indicated that $\mathrm{Fe}$ ions occupy the $\mathrm{Zn}$ ions sites in the hexagonal wurtzite structure and no impurity phase appears.

The morphology and microstructure of the samples were observed through HRTEM. The images of all samples reveal the presence of randomly distributed ellipsoidal shape nanoparticles. Figure 2(a) shows the HRTEM image of the $\mathrm{Zn}_{0.95} \mathrm{Fe}_{0.05} \mathrm{O}$; it can be seen that the sample consists of ellipsoidal shape particles, and well dispersed with smooth surface and uniform size, the diameter of the nanoparticles ranges from 10 to $40 \mathrm{~nm}$, with an average diameter approximately $25 \mathrm{~nm}$. The crystalline quality improves since CTAB promotes the establishment of a net surface charge onto the nanocrystals preventing their aggregation. Figure 2(b) shows a typical HRTEM image of $\mathrm{Zn}_{0.95} \mathrm{Fe}_{0.05} \mathrm{O}$ nanoparticles. The resolved lattice plane extending through the image confirms that the particle is crystallized. Figure 2(b) displays the clear lattice fringes; the interplanar distance is about $0.263 \mathrm{~nm}$, 


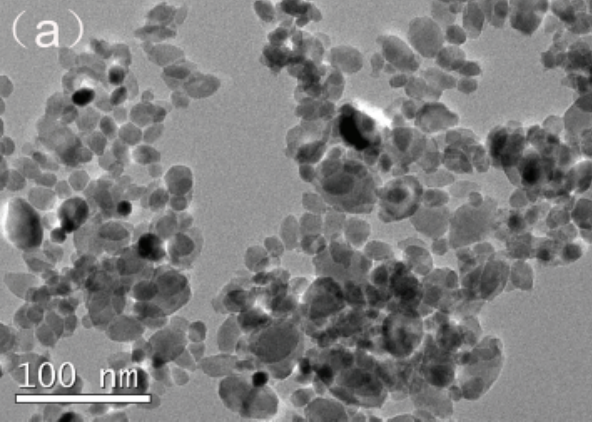

(a)

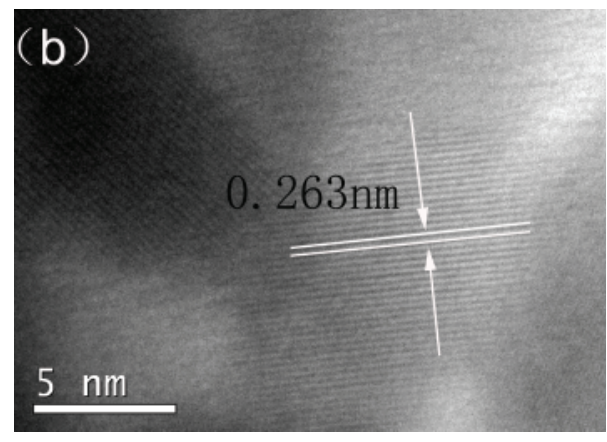

(b)

FIGURE 2: HRTEM images of the $\mathrm{Zn}_{0.95} \mathrm{Fe}_{0.05} \mathrm{O}$ nanoparticles.

which is in good agreement with the $d$-spacing of (002) planes of hexagonal wurtzite $\mathrm{ZnO}$ structure. The value of lattice spacing is greater than that of pure $\mathrm{ZnO}(0.26 \mathrm{~nm})$. The HRTEM analysis is consistent with the XRD results, which further indicates that all the Fe ions successfully substituted for the lattice site of $\mathrm{Zn}^{2+}$ in the hexagonal wurtzite structure and no impurity phase appeared.

In order to determine the elements of the prepared samples, EDS analysis was performed. Figure 3 shows the EDS patterns of $\mathrm{Zn}_{0.95} \mathrm{Fe}_{0.05} \mathrm{O}$ sample. The EDS spectrum indicates that the as-prepared nanoparticles mainly contain $\mathrm{Fe}, \mathrm{Zn}$, and $\mathrm{O}$ three elements. The characteristic peaks of $\mathrm{O}$ appeared at $0.5 \mathrm{keV}$ and the characteristic peaks of $\mathrm{Zn}$ appeared at 1 and $8.7 \mathrm{keV}$. The characteristic peaks of $\mathrm{Cu}$ appeared at $0.9,8$ and $8.9 \mathrm{keV}$. The Fe signal at $0.7,6.4$, and $7.1 \mathrm{keV}$ was observed in the Fe-doped $\mathrm{ZnO}$ nanoparticles. Apart from that, the $\mathrm{Cu}$ and $\mathrm{C}$ peaks in the EDS originate from the TEM micromesh grid. The EDS results further verify $\mathrm{XRD}$ conclusion; this indicates that $\mathrm{Fe}$-doped $\mathrm{ZnO}$ diluted magnetic semiconductor was successfully synthesized by hydrothermal method and $\mathrm{Fe}^{3+}$ in the sample occupied the place of $\mathrm{Zn}^{2+}$.

Raman spectra are a versatile technique for detecting the incorporation of dopants and the resulted defects and lattice disorder in the host lattice. In order to further confirm the phase transition and the defect chemistry variation after Fe-doped $\mathrm{ZnO}$, Raman spectra of the as-prepared products were measured with an excitation wavelength of $532 \mathrm{~nm}$ at room temperature. Wurtzie structure $\mathrm{ZnO}$ as a $n$-type II-VI semiconductor with the space group $6_{3} \mathrm{mc}$, has zone center optical phononmodes: $\Gamma_{\text {opt }}=A_{1}+2 B_{1}+E_{1}+2 E_{2}$ [21], where $A_{1}, E_{1}$, and $E_{2}$ are Raman active and $B_{1}$ is Raman forbidden. $A_{1}$ and $E_{1}$ modes are polar and split into the transverse optical (TO) and longitudinal optical (LO) phonons, and $E_{2}$ mode consists of two modes: $E_{2}$ high which is associated with the vibration of oxygen atoms and $E_{2}$ low attributed to the $\mathrm{Zn}$ sublattices.

Room temperature Raman spectrum of all the synthesized samples is presented in Figure 4. The spectra reveal that all the major peaks which are the characteristics of vibrational modes in $\mathrm{ZnO}$ exist in all samples. For all the samples, Raman

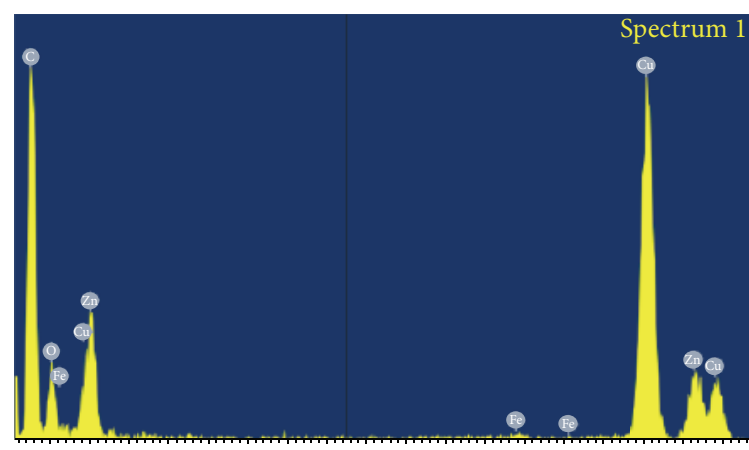

$\begin{array}{llllllllllllllllll}0.5 & 1 & 1.5 & 2 & 2.5 & 3 & 3.5 & 4 & 4.5 & 5 & 5.5 & 6 & 6.5 & 7 & 7.5 & 8 & 8.5 & 9\end{array}$

$(\mathrm{keV})$

Full scale 308 cts cursor 4.251 ( 0 cts)

FIGURE 3: EDS patterns of the $\mathrm{Zn}_{0.95} \mathrm{Fe}_{0.05} \mathrm{O}$ nanoparticles.

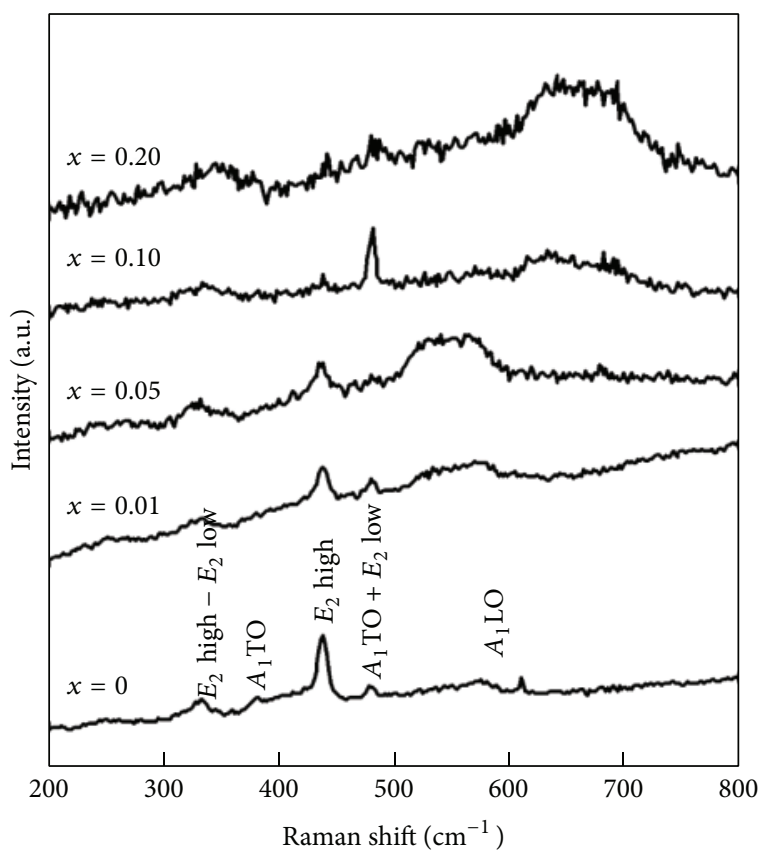

FIGURE 4: Raman patterns of the $\mathrm{Zn}_{1-x} \mathrm{Fe}_{x} \mathrm{O}$ nanoparticles. 


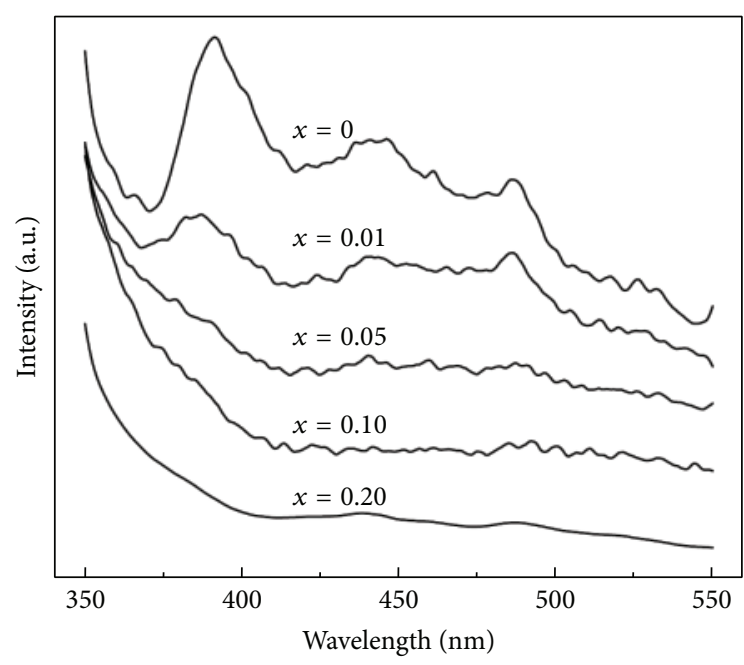

FIGURE 5: Photoluminescence spectra of the $\mathrm{Zn}_{1-x} \mathrm{Fe}_{x} \mathrm{O}$ nanoparticles.

peak at $332 \mathrm{~cm}^{-1}$ is attributed to the second order Raman mode arising from zone boundary phonons $E_{2}$ high- $E_{2}$ low, the peak at $381 \mathrm{~cm}^{-1}$ is assigned to the fundamental optical mode $A_{1} \mathrm{TO}$, and the peak at $444 \mathrm{~cm}^{-1}$ is the $E_{2}$ high mode, whereas peak at about $478 \mathrm{~cm}^{-1}$ is thought as originated from two phonon process, which correspond to $A_{1} \mathrm{TO}+E_{2}$ low mode. Moreover, for the $\mathrm{Zn}_{0.99} \mathrm{Fe}_{0.01} \mathrm{O}$ and $\mathrm{Zn}_{0.95} \mathrm{Fe}_{0.05} \mathrm{O}$ samples, a broad hump at $574 \mathrm{~cm}^{-1}$ is $A_{1} \mathrm{LO}$ symmetry modes $[11,22,23]$. And for the $\mathrm{Zn}_{0.90} \mathrm{Fe}_{0.10} \mathrm{O}$ and $\mathrm{Zn}_{0.80} \mathrm{Fe}_{0.20} \mathrm{O}$ samples, a broad peak centered at $640 \mathrm{~cm}^{-1}$ is related to intrinsic host-lattice defects after doping and it is also a powerful evidence to prove $\mathrm{Fe}^{3+}$ occupation at $\mathrm{Zn}^{2+}$ sites in the $\mathrm{ZnO}$ lattice $[24,25]$. Besides, with increasing the content of $\mathrm{Fe}^{3+}$ doping in the samples, there is shift in all peaks towards higher frequency region, broaden asymmetrically and weakened peak intensity. This shift can be due to strain, phonon confinement by boundaries, and the force constant changes caused by the less defects or impurities.

In these modes, the $E_{2}$ high peak in all the samples is attributed to the standard mode in wurtzite structure, which indicates that $\mathrm{Fe}$-doped $\mathrm{ZnO}$ nanoparticles keep a good hexagonal $\mathrm{ZnO}$ structure. Moreover, $E_{2}$ high mode is very sensitive to the stress in the crystal [24]. From Figure 4, the peaks at $444 \mathrm{~cm}^{-1}$ of $E_{2}$ high mode are lowered in the intensity with the more Fe content, which due to the radius of $\mathrm{Fe}^{3+}(0.063 \mathrm{~nm})$ smaller than radius of $\mathrm{Zn}^{2+}(0.074 \mathrm{~nm})$, and after being doped with $\mathrm{Fe}^{3+}$, it can cause the lattice expansion, defects, and the stress increase [26].

Figure 5 depicts PL spectra of Fe-doped $\mathrm{ZnO}$ nanoparticles at room temperature. For comparison, PL spectrum of undoped $\mathrm{ZnO}$ sample is also given. The pure $\mathrm{ZnO}$ sample contains six main emission peaks, including three obvious broad bands centered at 390,440, and $490 \mathrm{~nm}$ and three comparatively weak emission peaks at 420,460 , and $525 \mathrm{~nm}$, respectively. The $1 \%$ sample exhibits similar emission to pure $\mathrm{ZnO}$. This illustrates that the $\mathrm{Zn}_{0.99} \mathrm{Fe}_{0.01} \mathrm{O}$ sample displays nearly the same structure of pure $\mathrm{ZnO}$. But the emission peak position of doped sample exhibits a slight blue shift with the

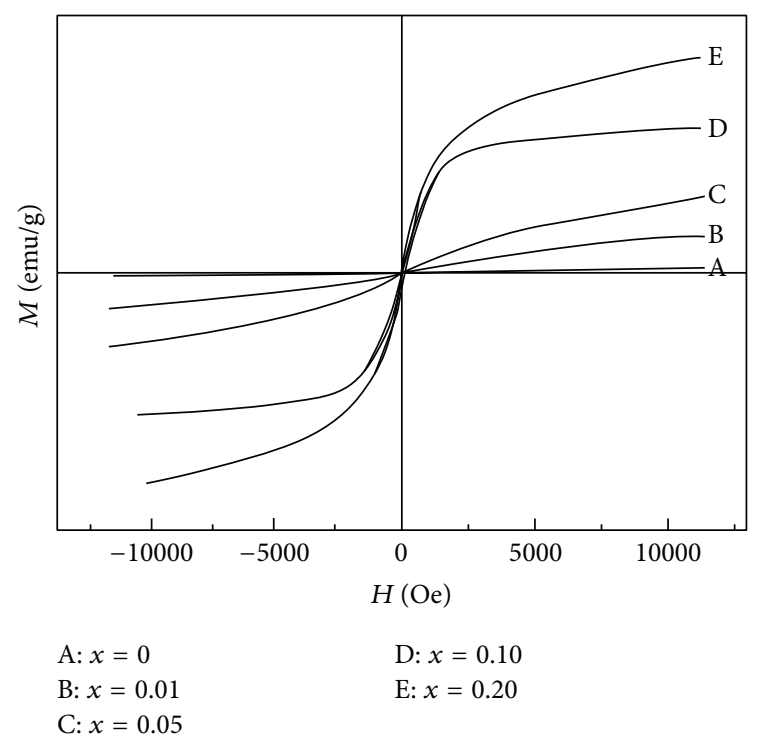

FIGURE 6: The magnetic hysteresis loops of the $\mathrm{Zn}_{1-x} \mathrm{Fe}_{x} \mathrm{O}$ nanoparticles.

increase of $\mathrm{Fe}^{3+}$ concentration, and this is attributed to defects or the oxygen vacancies in $\mathrm{ZnO}$ induced by $\mathrm{Fe}^{3+}$ doping. In addition, the visible light (VL) emission band is also suppressed with the increase of the $\mathrm{Fe}^{3+}$ concentration. The strong ultraviolet (UV) emission band at $390 \mathrm{~nm}(3.18 \mathrm{eV})$ and the weak violet emission peak located at $420 \mathrm{~nm}(2.95 \mathrm{eV})$ originate from excitonic recombination corresponding to the near-band-edge emission (NBE) of wide band gap of $\mathrm{ZnO}$, because of the quantum confinement effect [27]. The strong blue emission bands centered at $440 \mathrm{~nm}(2.8 \mathrm{eV})$ and the weak blue emission peak at $460 \mathrm{~nm}(2.69 \mathrm{eV})$ are attributed to the transitions between the shallow donor levels of the interstitial $\mathrm{Zn}$ to the top of the valence band [14] or the transitions between shallow acceptor levels of oxygen vacancies and shallow donor levels of zinc vacancy [28]. The blue-green bands centered at $490 \mathrm{~nm}(2.55 \mathrm{eV})$ for samples are ascribed to the transition between the deep donor level of oxygen vacancy, which is close to the bottom of the conduction band of about $0.8 \sim 0.9 \mathrm{eV}$, to the valence band $[28,29]$. The weak green emission peak at $525 \mathrm{~nm}(2.36 \mathrm{eV})$ is possibly assigned to positively charged electron transition and surface traps mediated by defects in the band gap [30]. PL spectrum analysis further illustrates that $\mathrm{Fe}$ ions are probably incorporated into the $\mathrm{ZnO}$ host matrix in the doped $\mathrm{ZnO}$ sample.

The related PL intensity of doped sample decreases rapidly with the increase of Fe doping concentration compared with undoped $\mathrm{ZnO}$, and the emission peak position intensity of $20 \% \mathrm{Fe}$-doped $\mathrm{ZnO}$ sample was annihilated; this is because the photogenerated electrons preferentially occupy the Fe ion induced trap centers, resulting in the quenching of luminescence [14].

Figure 6 shows the magnetic hysteresis $(\mathrm{M}-\mathrm{H})$ loops of the $\mathrm{Zn}_{1-x} \mathrm{Fe}_{x} \mathrm{O}$ nanoparticles with different doping consistency $(x=0,0.01,0.05,0.10$, and 0.20$)$ measured at room temperature. The magnetic hysteresis loops of $\mathrm{ZnO}$ 
and lower doped $\mathrm{ZnO}(x=0.01$ and 0.05$)$ samples pass origin of coordinates, and the remanent magnetization $\left(M_{r}\right)$, and coercivity $\left(H_{c}\right)$ are zero. It suggests that these samples show paramagnetic behaviors at room temperature. While the higher doped $\mathrm{ZnO}(x=0.10$ and 0.20$)$ samples exhibit obvious ferromagnetic behaviors. The saturation magnetization values are $0.74 \mathrm{emu} / \mathrm{g}$ and $1.74 \mathrm{emu} / \mathrm{g}$ and the coercive force values are $90 \mathrm{Oe}$ and $78 \mathrm{Oe}$, respectively, for $\mathrm{ZnO}(x=0.10$ and 0.20). It is evident from Figure 6 that a transition from the paramagnetic state to the ferromagnetism state occurs. The saturation magnetization of $\mathrm{Zn}_{1-x} \mathrm{Fe}_{x} \mathrm{O}$ nanoparticles increases with the increasing of Fe doping concentration compared with pure $\mathrm{ZnO}$.

The room temperature ferromagnetism of the $\mathrm{Zn}_{1-x} \mathrm{Fe}_{x} \mathrm{O}$ nanoparticles could arise from two possible sources. One is extrinsic magnetism and the other is intrinsic magnetism. Extrinsic source includes the formation of clusters of transition elements or secondary phase. Exchange interactions come under intrinsic source of magnetism. But the XRD results of the $\mathrm{Zn}_{1-x} \mathrm{Fe}_{x} \mathrm{O}$ nanoparticles suggest no traces of impurity or secondary phases (these parasitic phases include the Fe clusters and any other phases like $\mathrm{Fe}_{2} \mathrm{O}_{3}, \mathrm{Fe}_{3} \mathrm{O}_{4}$, etc.). Thus, the possibility of ferromagnetism due to the clusters of transition elements or secondary phases in the samples could be ruled out. Hence, the obtained ferromagnetism is an intrinsic magnetic property of the $\mathrm{Zn}_{1-x} \mathrm{Fe}_{x} \mathrm{O}$ nanoparticles. It is evident from the XRD analysis that $\mathrm{Fe}$ is incorporated into the $\mathrm{ZnO}$ lattice. In view of the $\mathrm{Fe}^{3+}$ ions substituted into $\mathrm{ZnO}$ lattice, the origin of magnetism in the samples is due to the exchange interaction between local spinpolarized electrons (such as the electrons of $\mathrm{Fe}^{3+}$ ions) and the conductive electrons. Such interaction can lead to the spin polarization of conductive electrons. Consequently, the spin-polarized conductive electrons undergo an exchange interaction with local spin-polarized electrons of $\mathrm{Fe}^{3+}$ ions. Thus, after a successive long-range exchange interaction, almost all $\mathrm{Fe}^{3+}$ ions exhibit the same spin direction, resulting in the ferromagnetism of the material [31].

\section{Conclusions}

(1) Diluted magnetic semiconductors $\mathrm{Zn}_{1-x} \mathrm{Fe}_{x} \mathrm{O}$ nanoparticles with different concentration $(x=0$, $0.01,0.05,0.10$, and 0.20 ) have been synthesized by hydrothermal method. The samples possess hexagonal wurtzite crystal structure with good crystallization, no other impurity phase appeared, and the morphology of samples is ellipsoidal shape nanoparticles with good dispersion.

(2) All the $\mathrm{Fe}^{3+}$ successfully substituted for the lattice site of $\mathrm{Zn}^{2+}$ and generates single-phase $\mathrm{Zn}_{1-x} \mathrm{Fe}_{x} \mathrm{O}$. The Raman spectra of the $\mathrm{Zn}_{1-x} \mathrm{Fe}_{x} \mathrm{O}$ nanoparticles occurs red shift, and the UV emission of photoluminescence spectra is annihilated with the increase of $\mathrm{Fe}^{3+}$ concentration. The ferromagnetic behaviors are found for all doped samples at room temperature.

\section{Conflict of Interests}

The authors declare that there is no conflict of interests regarding the publication of this paper.

\section{Acknowledgments}

This work was supported by the National Natural Science Foundation of China (no. 51261015) and the Natural Science Foundation of Gansu Province, China (no. 1308RJZA238).

\section{References}

[1] H. Ohno, "Making nonmagnetic semiconductors ferromagnetic," Science, vol. 281, no. 5379, pp. 951-956, 1998.

[2] S. J. Pearton, D. P. Norton, M. P. Ivill et al., "ZnO doped with transition metal ions," IEEE Transactions on Electron Devices, vol. 54, no. 5, pp. 1040-1048, 2007.

[3] A. Moezzi, A. M. McDonagh, and M. B. Cortie, "Zinc oxide particles: synthesis, properties and applications," Chemical Engineering Journal, vol. 185-186, pp. 1-22, 2012.

[4] D. Chu, Y. Masuda, T. Ohji, and K. Kato, "Formation and photocatalytic application of $\mathrm{ZnO}$ nanotubes using aqueous solution," Langmuir, vol. 26, no. 4, pp. 2811-2815, 2010.

[5] J. Zhang, S. Wang, M. Xu et al., "Hierarchically porous $\mathrm{ZnO}$ architectures for gas sensor application," Crystal Growth and Design, vol. 9, no. 8, pp. 3532-3537, 2009.

[6] X. J. Liu, X. Y. Zhu, C. Song, F. Zeng, and F. Pan, "Intrinsic and extrinsic origins of room temperature ferromagnetism in Nidoped ZnO films," Journal of Physics D: Applied Physics, vol. 42, no. 3, Article ID 035004, 2009.

[7] J. R. Neal, A. J. Behan, R. M. Ibrahim et al., "Room-temperature magneto-optics of ferromagnetic transition-metal-doped $\mathrm{ZnO}$ thin films," Physical Review Letters, vol. 96, no. 19, Article ID 197208, pp. 1-4, 2006.

[8] X. H. Huang, G. H. Li, B. Q. Cao, M. Wang, and C. Hao, "Morphology evolution and CL property of Ni-doped zinc oxide nanostructures with room-temperature ferromagnetism," Journal of Physical Chemistry C, vol. 113, no. 11, pp. 4381-4385, 2009.

[9] S. J. Pearton, D. P. Norton, K. Ip, Y. W. Heo, and T. Steiner, "Recent progress in processing and properties of $\mathrm{ZnO}$," Progress in Materials Science, vol. 50, no. 3, pp. 293-340, 2005.

[10] A. B. Djurišić, X. Chen, Y. H. Leung, and A. Man Ching $\mathrm{Ng}$, "ZnO nanostructures: growth, properties and applications," Journal of Materials Chemistry, vol. 22, no. 14, pp. 6526-6535, 2012.

[11] F. Decremps, J. Pellicer-Porres, A. M. Saitta, J. Chervin, and A. Polian, "High-pressure Raman spectroscopy study of wurtzite ZnO," Physical Review B: Condensed Matter and Materials Physics, vol. 65, no. 9, pp. 092101-092105, 2002.

[12] A. Alsaad, "Structural, electronic and magnetic properties of Fe, $\mathrm{Co}, \mathrm{Mn}$-doped $\mathrm{GaN}$ and $\mathrm{ZnO}$ diluted magnetic semiconductors," Physica B: Condensed Matter, vol. 440, pp. 1-9, 2014.

[13] C. Yilmaz and U. Unal, "Electrochemical deposition of $\mathrm{Mn}: \mathrm{ZnO}$ films under hydrothermal conditions," Journal of the Electrochemical Society, vol. 160, no. 4, pp. D163-D167, 2013.

[14] M. V. Limaye, S. B. Singh, R. Das, P. Poddar, and S. K. Kulkarni, "Room temperature ferromagnetism in undoped and Fe doped $\mathrm{ZnO}$ nanorods: microwave-assisted synthesis," Journal of Solid State Chemistry, vol. 184, no. 2, pp. 391-400, 2011. 
[15] G. Lawes, A. S. Risbud, A. P. Ramirez, and R. Seshadri, "Absence of ferromagnetism in Co and Mn substituted polycrystalline ZnO," Physical Review B: Condensed Matter and Materials Physics, vol. 71, no. 4, Article ID 045201, 2005.

[16] Y. T. Prabhu, V. Kumar, and K. V. Rao, "Effect of Fe doping on structural, optical and magnetic properties of $\mathrm{ZnO}$ nanoparticles derived by surfactant assisted combustion synthesis," Advanced Science, Engineering and Medicine, vol. 5, no. 3, pp. 198-205, 2013.

[17] F. Ahmed, S. Kumar, N. Arshi, M. S. Anwar, and B. Heun Koo, "Morphological evolution between nanorods to nanosheets and room temperature ferromagnetism of $\mathrm{Fe}$-doped $\mathrm{ZnO}$ nanostructures," CrystEngComm, vol. 14, no. 11, pp. 4016-4026, 2012.

[18] V. K. Sharma and G. D. Varma, "Fe clusters as origin of ferromagnetism in hydrogenated $\mathrm{Zn}_{1-x} \mathrm{Fe}_{x} \mathrm{O}$ ( $\left.\mathrm{x}=0.02 \& 0.05\right)$ samples," Advanced Materials Letters, vol. 3, no. 2, pp. 126-129, 2012.

[19] J. J. Beltrán, J. A. Osoriol, C. A. Barrerol, C. B. Hanna, and A. Punnoose, "Magnetic properties of Fe doped, Co doped, and $\mathrm{Fe}+\mathrm{Co}$ co-doped ZnO," Journal of Applied Physics, vol. 113, no. 17, Article ID 17C308, 2013.

[20] A. Baranowska-Korczyc, A. Reszka, K. Sobczak et al., "Magnetic Fe doped $\mathrm{ZnO}$ nanofibers obtained by electrospinning," Journal of Sol-Gel Science and Technology, vol. 61, no. 3, pp. 494-500, 2012.

[21] T. C. Damen, S. P. S. Porto, and B. Tell, "Raman effect in zinc oxide," Physical Review, vol. 142, no. 2, pp. 570-574, 1966.

[22] A. Singhal, S. N. Achary, J. Manjanna, S. Chatterjee, P. Ayyub, and A. K. Tyagi, "Chemical synthesis and structural and magnetic properties of dispersible cobalt- and nickel-doped ZnO nanocrystals," The Journal of Physical Chemistry C, vol. 114, no. 8, pp. 3422-3430, 2010.

[23] B. N. Mavrin, L. N. Demyanets, and R. M. Zakalukin, "Raman spectroscopy and Fermi resonance in Mn-doped $\mathrm{ZnO}$ bulk single crystal," Physics Letters A: General, Atomic and Solid State Physics, vol. 374, no. 39, pp. 4054-4056, 2010.

[24] B. Zhang, S. Zhou, H. Wang, and Z. Du, "Raman scattering and photoluminescence of Fe-doped $\mathrm{ZnO}$ nanocantilever arrays," Chinese Science Bulletin, vol. 53, no. 11, pp. 1639-1643, 2008.

[25] C. Bundesmann, N. Ashkenov, M. Schubert et al., "Raman scattering in $\mathrm{ZnO}$ thin films doped with $\mathrm{Fe}, \mathrm{Sb}, \mathrm{Al}, \mathrm{Ga}$, and $\mathrm{Li}$," Applied Physics Letters, vol. 83, no. 10, pp. 1974-1976, 2003.

[26] D. Shuang, X. X. Zhu, J. B. Wang, X. L. Zhong, G. J. Huang, and $\mathrm{C} . \mathrm{He}$, "The influence of $\mathrm{Mn}$ content on luminescence properties in $\mathrm{Mn}$-doped $\mathrm{ZnO}$ films deposited by ultrasonic spray assisted chemical vapor deposition," Applied Surface Science, vol. 257, no. 14, pp. 6085-6088, 2011.

[27] K. Vanheusden, W. L. Warren, C. H. Seager, D. R. Tallant, J. A. Voigt, and B. E. Gnade, "Mechanisms behind green photoluminescence in $\mathrm{ZnO}$ phosphor powders," Journal of Applied Physics, vol. 79, no. 10, pp. 7983-7990, 1996.

[28] G. Song, X. Fang, and H. Liang, "Effect of $\mathrm{O}_{2} /$ Ar ratio on blue photoluminescence spectrum of nanocrystalline zno films," Spectroscopy and Spectral Analysis, vol. 30, no. 3, pp. 591-594, 2010.

[29] H. Chen, J. Ding, and S. Ma, "Violet and blue-green luminescence from Ti-doped $\mathrm{ZnO}$ films deposited by $\mathrm{RF}$ reactive magnetron sputtering," Superlattices and Microstructures, vol. 49, no. 2, pp. 176-182, 2011.

[30] J. Wang and L. Gao, "Hydrothermal synthesis and photoluminescence properties of $\mathrm{ZnO}$ nanowires," Solid State Communications, vol. 132, no. 3-4, pp. 269-271, 2004.
[31] R. Elilarassi and G. Chandrasekaran, "Synthesis and characterization of ball milled Fe-doped $\mathrm{ZnO}$ diluted magnetic semiconductor," Optoelectronics Letters, vol. 8, no. 2, pp. 109$112,2012$. 

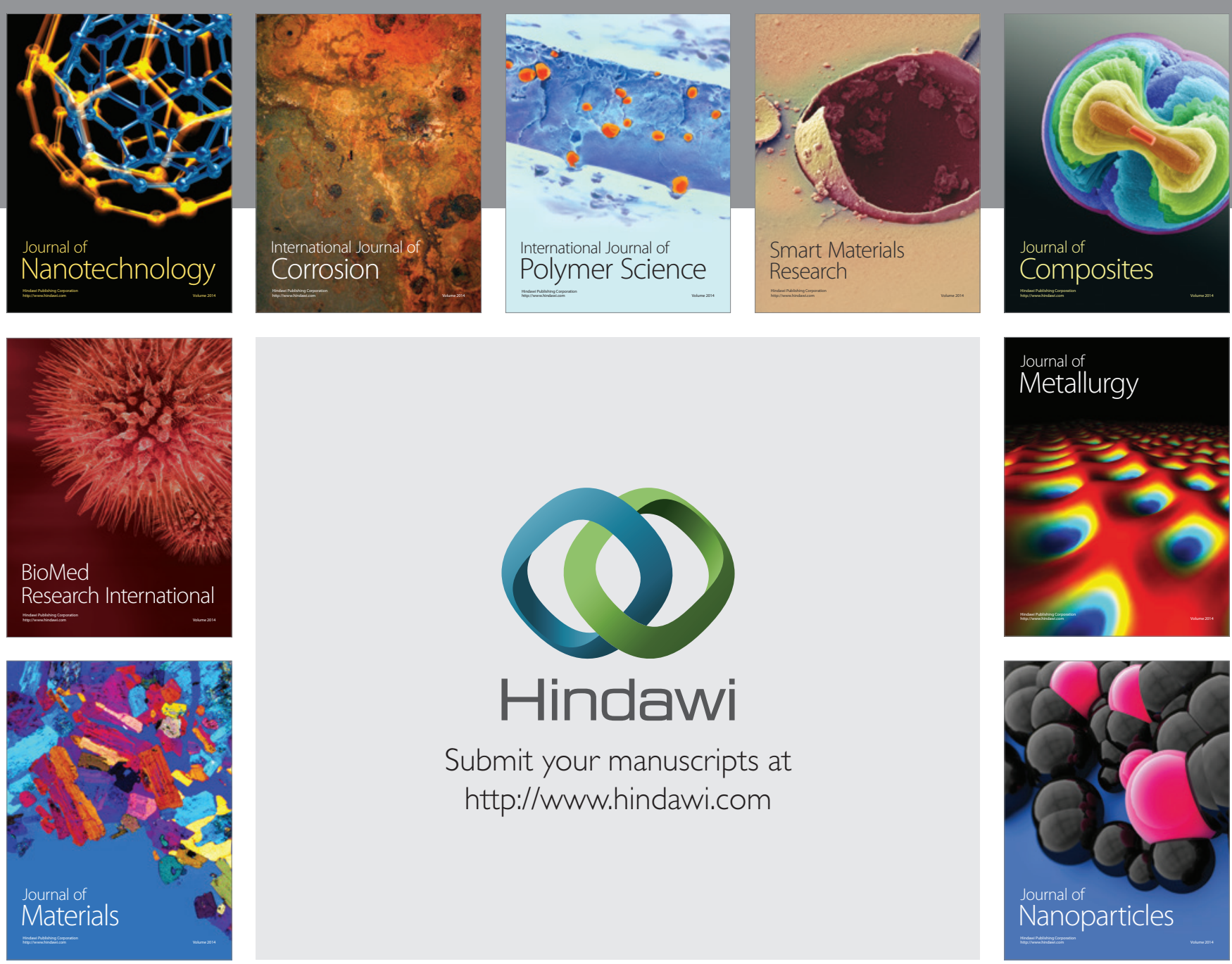

Submit your manuscripts at http://www.hindawi.com
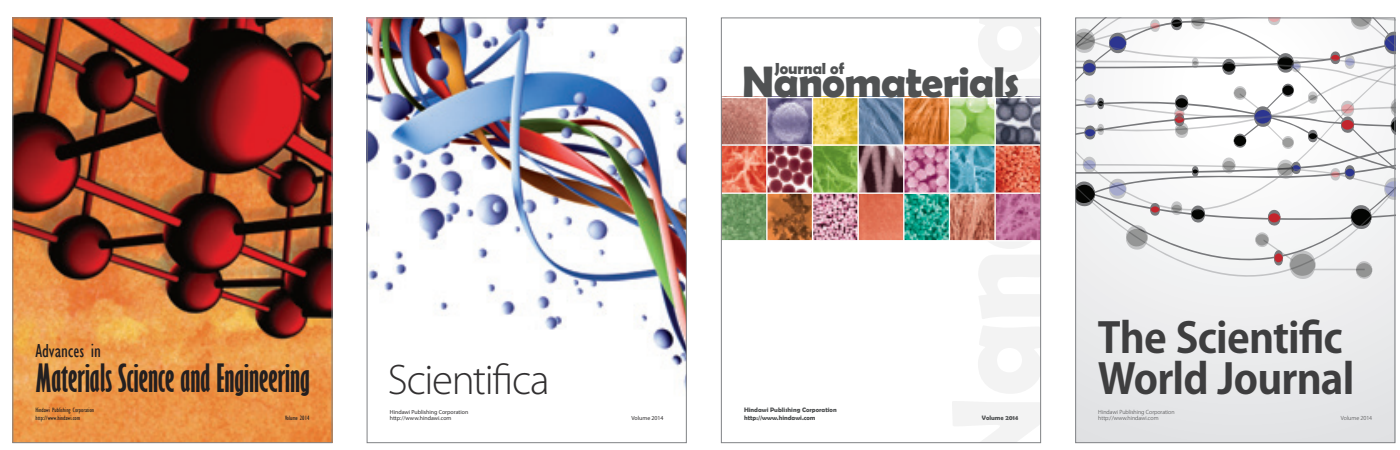

\section{The Scientific World Journal}
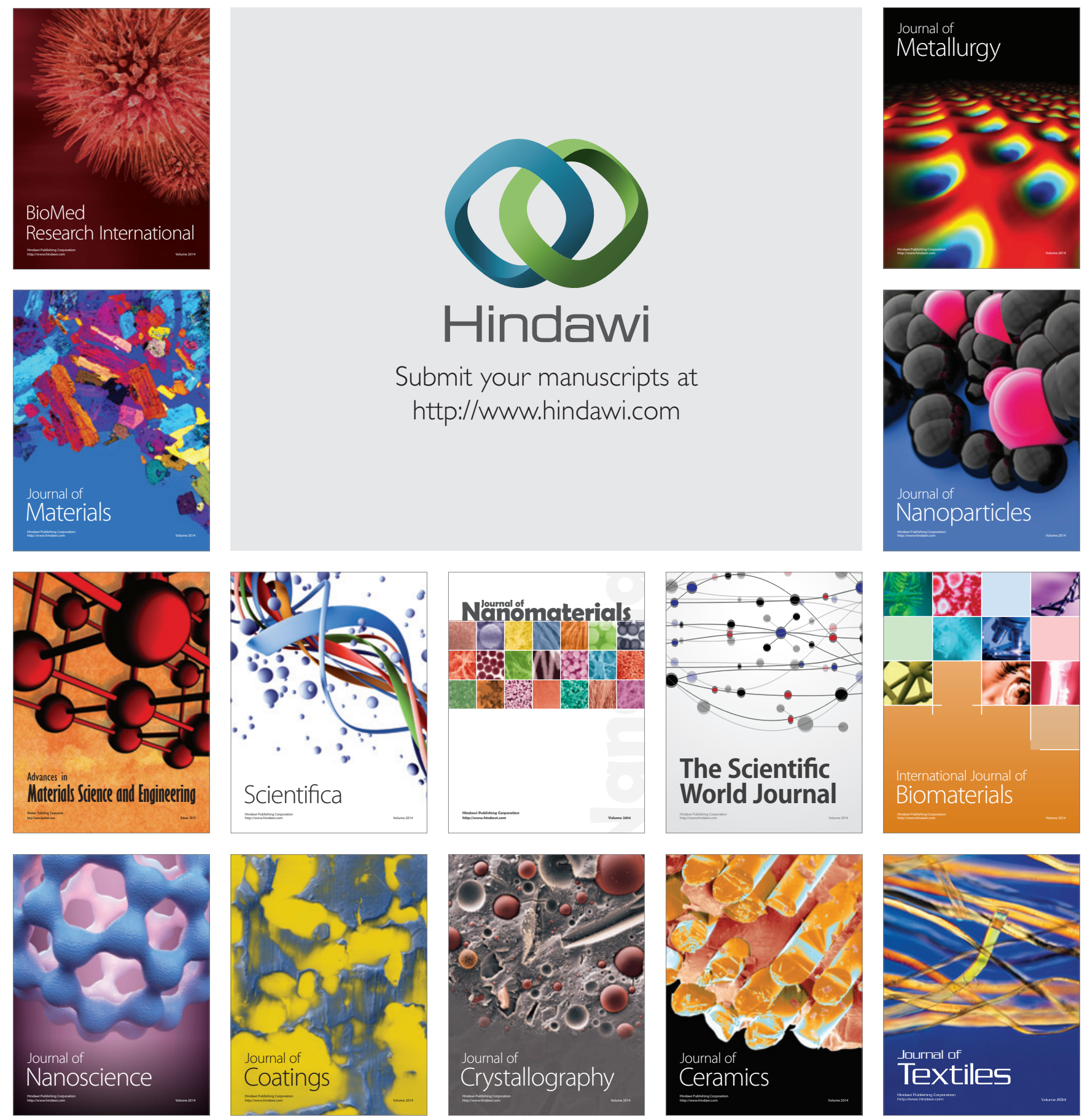